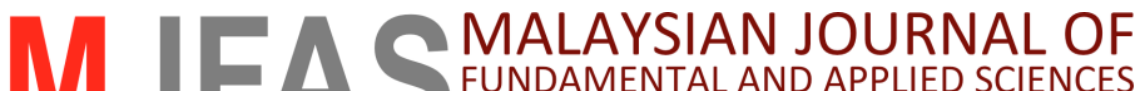

\section{Effect of gravity modulation on mixed convection flow of second grade fluid with different shapes of nanoparticles}

\author{
Noraihan Afiqah Rawi, Mohd Rijal llias, Zaiton Mat Isa, Sharidan Shafie* \\ Department of Mathematical Sciences, Faculty of Science, Universiti Teknologi Malaysia, 81310 UTM Johor Bahru, Johor, Malaysia
}

* Corresponding author: sharidan@utm.my

\section{Article history}

Received 5 March 2017

Accepted 2 April 2017

\begin{abstract}
The problem of unsteady mixed convection flow of second grade fluid over an inclined stretching plate under the influence of different shapes of nanoparticles is studied in this paper. The influence of gravity modulation is also considered. Carboxymethyl cellulose solution (CMC) is chosen as the nonNewtonian base fluid. Based on Tiwari-Das nanofluid model, the governing partial differential equations are transformed into a system of ordinary differential equations and solved numerically using an implicit finite difference scheme. The effect of different shapes and volume fraction of solid nanoparticles on the enhancement of convective heat transfer of second grade nanofluid associated with the effect amplitude of modulation, frequency of oscillation, and material parameter is discussed in details. The results indicated that, the needle-shaped nanoparticles give the highest enhancement on the heat transfer of second grade nanofluid compared to sphere and disk-shaped nanoparticles.
\end{abstract}

Keywords: Nanofluid, second grade fluid, inclined stretching plate, numerical solution

@ 2017 Penerbit UTM Press. All rights reserved

\section{INTRODUCTION}

The study of non-Newtonian fluids has become more evident over the past decades due to widely applications in engineering and industrial. Non-Newtonian fluids is a broad class of fluids in which the relation between the shear stress and the shear rate is nonlinear and hence cannot represents a single constitutive relation. In the literature, a number of non-Newtonian fluid models including micropolar fluid, second grade fluid, Jeffrey fluid and Casson fluids, types of nonNewtonian fluids have become very popular. Recently, the rheological model of second grade fluid has been widely studied by the researchers in view of its simplicity. Hsu et al. (1999) numerically investigated the second-grade viscoelastic fluid on the transient mixed convection flow with the combined effects of the Reynolds number, elastic number and the Richardson number. Also, Mushtaq et al. (2007) presented the effects of thermal buoyancy on the second grade fluid flow along a nonisothermal stretched vertical surface. Hayat and Qasim (2011) solved the problem of mixed convection boundary layer flow of a magnetohydrodynamic second grade fluid over an unsteady permeable stretching sheet by using homotopy analysis method (HAM). Later, Qasim et al. (2012) considered the effect of thermal radiation on the heat transfer analysis of the steady flow of viscoelastic fluid along an inclined stretching surface. Besides that, Turkyilmazoglu (2013) investigated on the mixed convection heat transfer and fluid flow of a MHD viscoelastic fluid over a permeable stretching surface using analytical approach. Recently, Hayat et al. (2014) solved the problem on the three-dimensional boundary layer mixed convection of viscoelastic fluid with convective boundary condition and thermal radiation.

The expansion on the research of mixed convection flow of second grade fluid has been continued by Ramzan and Bilal (2015) by considering the new approach in the presence of nanoparticles. The resulting nonlinear momentum, heat and concentration equations involving the effect of Brownian motion and thermophoresis and solved using homotopy analysis method. Nanofluid can be described as solid-liquid composite materials consisting of solid nanoparticles with size typically of 1-100 $\mathrm{nm}$ suspended in the conventional fluid such as oil, water and ethylene glycol mixture. Numerous models and methods have been proposed in the previous studies to investigate the convective flows of nanofluid. Among those investigations, the models suggested by Buongiorno (2006) and Tiwari and Das (2007) are the most popular. Nanofluid have become a potentially useful in many industrial applications such as coolants in automotive, microchips cooling, nano drug delivery, cancer therapeutics, extraction of geothermal power and others (see Wong and De Leon (2010)). Researchers usually use nanoparticles of spherical shapes. However in terms of applications and significance, spherical shaped nanoparticles are limited. For example, investigation by Karagoz et al. (2014) successfully showed that, in the delivery of drug to the breast cancer cells, the cylindrical shaped nanoparticles are seven times more deadly than traditional spherical shaped nanoparticles. To the best of author knowledge, numerical studies on different shapes of nanoparticles contained in carboxymethyl cellulose solution (CMC) as the base fluids is not reported yet.

Therefore, the aim of this present problem is to investigate the influence of different shapes of copper nanoparticles together with the effect of material parameter, solid nanoparticles volume fraction, amplitude of modulation and frequency of oscillation on the mixed convection flow of second grade nanofluid past an inclined stretching sheet. In this paper, carboxymethyl cellulose solution (CMC) is considered as the second grade base fluid with copper $(\mathrm{Cu})$ nanoparticles of different shapes. CMC is a cellulose derivative with a variety of different end-uses in numerous industries, for example in drilling fluids, it is appropriate for increasing the viscosity, controlling the mud fluid loss, and maintaining adequate flow properties at high temperature, salinity and pressure. Previous studies on the rheological properties of CMC solutions reported by Benchabane and Bekkour 
(2008) found that, at the lowest concentration, the CMC solutions presented nearly Newtonian behaviour while the pseudoplastic, thixotrophic and viscoelastic responses at the strong concentration.

\section{MATHEMATICAL FORMULATION}

\section{Governing Equation}

The unsteady mixed convection flow of incompressible second grade fluid past an inclined stretching sheet with the presence of copper nanoparticles is presented in this problem. The $x$-axis is extending along the surface with inclination angle, $\alpha$ to the vertical in the upward direction and $y$-axis is normal to the surface. The plate is assumed has a linear velocity, $u_{w}(x)$ moves in $x$-direction of the flow and temperature of the plate varies linearly with the distance $x$ along the plate, where $T_{w}(x)>T_{\infty}$ with $T_{w}(x)$ being the temperature of the plate and $T_{\infty}$ being the uniform temperature of the ambient second grade fluid. The physical model is presented in the Fig. 1.

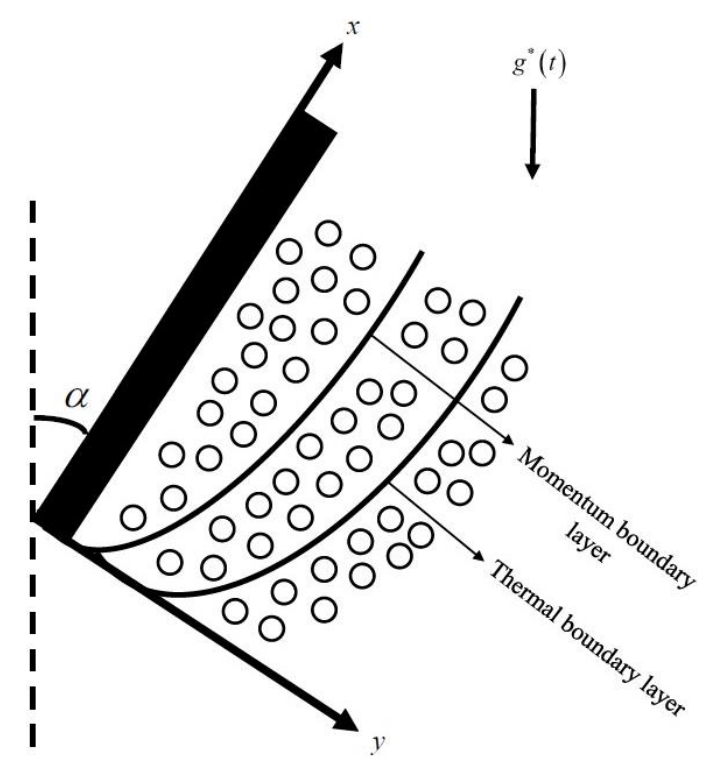

Fig. 1 Physical model and coordinate system

Under the usual boundary layer and Boussinesq approximations, the basic governing equations of second grade fluid with the present of copper nanoparticles can be written as

$$
\begin{gathered}
\frac{\partial u}{\partial x}+\frac{\partial v}{\partial y}=0 \\
\rho_{n f}\left[\frac{\partial u}{\partial t}+u \frac{\partial u}{\partial x}+v \frac{\partial u}{\partial y}\right]=\mu_{n f} \frac{\partial^{2} u}{\partial y^{2}} \\
+g^{*}(t)(\rho \beta)_{n f}\left(T-T_{\infty}\right) \cos \alpha \\
+\alpha_{1}\left[\frac{\partial^{3} u}{\partial t \partial y^{2}}+u \frac{\partial^{3} u}{\partial x \partial y^{2}}+\frac{\partial u}{\partial x} \frac{\partial^{2} u}{\partial y^{2}}+\frac{\partial u}{\partial y} \frac{\partial^{2} v}{\partial y^{2}}+v \frac{\partial^{3} u}{\partial y^{3}}\right] \\
\left(\rho C_{p}\right)_{n f} \frac{\partial T}{\partial t}+u \frac{\partial T}{\partial x}+v \frac{\partial T}{\partial y}=k_{n f} \frac{\partial^{2} T}{\partial y^{2}},
\end{gathered}
$$

where $u$ and $v$ are the velocity components along $x$ - and $y$-axes, $\rho_{n f}$ is the density of nanofluid, $\mu_{n f}$ is the effective viscosity of nanofluid, $\beta_{n f}$ is the thermal expansion of nanofluid, $\alpha_{1}$ is the material parameter of second grade fluid, $T$ is the temperature, $\left(C_{p}\right)_{n f}$ is the specific heat of the nanofluid at constant pressure and $k_{n f}$ is the effective thermal conductivity of the nanofluid.
The initial and boundary conditions for the present problem are

$$
\begin{aligned}
& t=0: u=v=0, T=T_{\infty} \text { for any } x, y, \\
& t>0: u_{w}(x)=c x, v=0, T=T_{w}=T_{\infty}+a x \text { at } y=0, \\
& u \rightarrow 0, \frac{\partial u}{\partial y} \rightarrow 0, T \rightarrow T_{\infty} \text { as } y \rightarrow \infty .
\end{aligned}
$$

Considering the effect of g-jitter, following Sharidan et al. (2006), the gravity acceleration, $g^{*}(t)$ is given by

$$
g^{*}(t)=g_{0}[1+\varepsilon \cos (\pi \omega t)] \mathbf{k}
$$

where $g_{0}$ is the time-averaged value of the gravitational acceleration, $g^{*}(t)$ acting along the direction on the unit vector $\mathbf{k}$ which is oriented in the upward direction, $\varepsilon$ is a scaling parameter, which gives the magnitude of the gravity modulation relative to $g_{0}, t$ is the time and $\omega$ is the frequency of oscillation of the g-jitter driven flow.

By substituting (5) into (2), the following momentum governing equation is obtained,

$$
\begin{aligned}
\frac{\partial u}{\partial t}+u \frac{\partial u}{\partial x} & +v \frac{\partial u}{\partial y}=\frac{\mu_{n f}}{\rho_{n f}} \frac{\partial^{2} u}{\partial y^{2}} \\
& +g_{0}[1+\varepsilon \cos (\pi \omega t)] \beta_{n f}\left(T-T_{\infty}\right) \cos \alpha \\
& +\frac{\alpha_{1}}{\rho_{n f}}\left[\frac{\partial^{3} u}{\partial t \partial y^{2}}+u \frac{\partial^{3} u}{\partial x \partial y^{2}}+\frac{\partial u}{\partial x} \frac{\partial^{2} u}{\partial y^{2}}+\frac{\partial u}{\partial y} \frac{\partial^{2} v}{\partial y^{2}}+v \frac{\partial^{3} u}{\partial y^{3}}\right]
\end{aligned}
$$

In Eqs. (3) and (6), the nanofluids constant are defined by,

$$
\begin{gathered}
\rho_{n f=}(1-\phi) \rho_{f}+\phi \rho_{s}, \\
(\rho \beta)_{n f}=(1-\phi)(\rho \beta)_{f}+\phi(\rho \beta)_{s}, \\
\left(\rho C_{p}\right)_{n f}=(1-\phi)\left(\rho C_{p}\right)_{f}+\phi\left(\rho C_{p}\right)_{s},
\end{gathered}
$$

where $\phi$ is the solid nanoparticles volume fraction and the subscripts $f$ and $s$ refer to second grade fluid as a base fluid and nanoparticles properties, respectively. In this study, Hamilton and Crosser (1962) model for both thermal conductivity and dynamic viscosity are used, which are valid for both spherical and non-spherical shapes nanoparticles. The effective dynamic viscosity is

$$
\mu_{n f}=\mu_{f}\left(1+a \phi+b \phi^{2}\right),
$$

where the constant values of $a$ and $b$ are depended on the particle shape as given in Table 1 (Timofeeva et al. (2009), Ellahi et al. (2016)) and $\mu_{f}$ is the dynamic viscosity of the base fluid.

Table 1 Constants $a$ and $b$ empirical shape factors.

\begin{tabular}{cccc}
\hline Model & Sphere & $\begin{array}{c}\text { Blade } \\
\text { (disk-shaped) }\end{array}$ & $\begin{array}{c}\text { Cylinder } \\
\text { (Needle-shaped) }\end{array}$ \\
\hline$a$ & 2.5 & 14.6 & 13.5 \\
$b$ & 6.2 & 123.3 & 904.4 \\
\hline
\end{tabular}

Next, the thermal conductivity of the nanofluid is given in the form of,

$$
\frac{k_{n f}}{k_{f}}=\frac{k_{s}+(n-1) k_{f}+(n-1)\left(k_{f}-k_{s}\right) \phi}{k_{s}+(n-1) k_{f}-\left(k_{f}-k_{s}\right) \phi}
$$

with $n$ as the empirical shape factor given by,

$$
n=\frac{3}{\psi_{*}}
$$

where $\psi_{*}$ is the sphericity defined as the ratio between the surface area of the sphere and surface area of the real particle with equal volumes. Following Timofeeva et al. (2009), the values of $\psi_{*}$ for different shape particles are given in Table 2. 
Table 2 Sphericity for different shapes of nanoparticles.

\begin{tabular}{cccc}
\hline Model & Sphere & $\begin{array}{c}\text { Blade } \\
\text { (disk-shaped) }\end{array}$ & $\begin{array}{c}\text { Cylinder } \\
\text { (Needle-shaped) }\end{array}$ \\
\hline$\psi_{*}$ & 1 & 0.36 & 0.62 \\
\hline
\end{tabular}

The complexity of the problem is reduced by introducing the following similarity transformations (Sharidan et al., 2006),

$\tau=\omega t, \eta=\left(\frac{c}{v_{f}}\right)^{1 / 2} y, \psi=\left(c v_{f}\right)^{1 / 2} x f(\tau, \eta), \theta(\tau, \eta)=\frac{\left(T-T_{\infty}\right)}{\left(T_{w}-T_{\infty}\right)}$,

where $\psi(x, y)$ is the stream function that satisfies the continuity equation can be defined as $u=\partial \psi / \partial y$ and $v=-\partial \psi / \partial x$. By employing the similarity transformations into the governing equations, the following transformed governing equations are obtained,

$$
\begin{aligned}
(1+ & \left.a \phi+b \phi^{2}\right) f^{\prime \prime \prime}+C_{1}\left[f f^{\prime \prime}-\left(f^{\prime}\right)^{2}\right]=C_{1} \Omega \frac{\partial f^{\prime}}{\partial \tau}-K \Omega \frac{\partial f^{\prime \prime \prime}}{\partial \tau} \\
+ & K\left[2 f^{\prime \prime \prime \prime \prime}-\left(f^{\prime \prime}\right)^{2}-f f^{(4)}\right] \\
+ & C_{2} \lambda[1+\varepsilon \cos (\pi \tau)] \theta \cos \alpha \\
& \frac{k_{n f}}{k_{f}} \theta^{\prime \prime}+C_{3} \operatorname{Pr}\left[f \theta^{\prime}-f^{\prime} \theta\right]=C_{3} \operatorname{Pr} \Omega \frac{\partial \theta}{\partial \tau},
\end{aligned}
$$

where the constants $\mathrm{C}_{1}, \mathrm{C}_{2}$ and $\mathrm{C}_{3}$ are defined as,

$$
\begin{gathered}
C_{1}=(1-\phi)+\phi \frac{\rho_{s}}{\rho_{f}}, C_{2}=(1-\phi)+\phi \frac{(\rho \beta)_{s}}{(\rho \beta)_{f}}, \\
C_{3}=(1-\phi)+\phi \frac{\left(\rho C_{p}\right)_{s}}{\left(\rho C_{p}\right)_{f}},
\end{gathered}
$$

subjected to the transformed boundary conditions,

$$
\begin{gathered}
f=0, f^{\prime}=1, \theta=1 \text { on } \eta=0 \\
f^{\prime} \rightarrow 0, f^{\prime \prime} \rightarrow 0, \theta \rightarrow 0 \text { as } \eta \rightarrow \infty .
\end{gathered}
$$

Here, $\operatorname{Pr}=\left(\frac{C_{p} \mu}{k}\right)_{f}$ is the Prandtl number, $K=\frac{\alpha_{1} c}{\mu_{f}}$ is the material parameter, $\Omega=\frac{\omega}{c}$ is the non-dimensional frequency and $\lambda$ is the mixed convection parameter are defined as,

$$
\lambda=\frac{g_{0} \beta_{T}\left[T_{w}(x)-T_{\infty}\right] x^{3} / v_{f}^{2}}{\left[u_{w}(x) x / v_{f}\right]^{2}}=\frac{G r_{x}}{\operatorname{Re}_{x}^{2}}
$$

with $G r_{x}$ and $\operatorname{Re}_{x}$ being the local Grashof number and Reynolds number, respectively. It is worth mentioning that for $\alpha_{1}=0$, the constitutive equation of second grade fluid reduced to the case of regular viscous fluid.

\section{Quantities of Physical Interest}

The quantities of engineering interest including the skin friction coefficient, $C_{f}$ and the local Nusselt number, $N u_{x}$

$$
C_{f}=\frac{\tau_{w}(x)}{\rho_{f} u_{w}^{2}}, N u_{x}=\frac{q_{w}(x) x}{k_{f}\left(T_{w}-T_{\infty}\right)},
$$

where $\tau_{w}(x)$ is the wall shear stress and $q_{w}(x)$ is the wall heat flux are given by,

$$
\begin{gathered}
\tau_{w}=\mu_{n f}\left(\frac{\partial u}{\partial y}\right)_{y=0}+\alpha_{1}\left(u \frac{\partial^{2} u}{\partial x \partial y}+v \frac{\partial^{2} u}{\partial y^{2}}-u \frac{\partial u \partial v}{\partial y \partial y}\right)_{y=0}, \\
q_{w}(x)=-k_{n f}\left(\frac{\partial T}{\partial y}\right)_{y=0} .
\end{gathered}
$$

The following dimensionless form of a skin friction coefficient and a local Nusselt number are obtained as,

$$
\begin{aligned}
C_{f} \operatorname{Re}_{x}^{1 / 2}= & \left(1+a \phi+b \phi^{2}\right) f^{\prime \prime} \\
& +K\left(3 f^{\prime}(\tau, 0) f^{\prime \prime}(\tau, 0)-f(\tau, 0) f^{\prime \prime \prime}(\tau, 0)\right), \\
& \frac{N u_{x}}{\operatorname{Re}_{x}^{1 / 2}}=-\frac{k_{n f}}{k_{f}} \theta^{\prime}(\tau, 0) .
\end{aligned}
$$

\section{RESULTS AND DISCUSSION}

The system of the partial differential Eqs. (11) and (12) together with the boundary conditions (13) are solved numerically using finite difference scheme known as Keller-box method. The effect of different values of parameters including material parameter, $K$, solid nanoparticles volume fraction, $\phi$, amplitude of modulation, $\varepsilon$ and frequency of oscillation, $\Omega$ together with the influence of different shapes of nanoparticles on the velocity and temperature profiles as well as the skin friction and heat transfer coefficients are analyzed and discussed in detail. Thermophysical properties of chosen base fluid and nanoparticles is presented in Table 3 (Lin et al., 2014).

Table 3 Thermophysical properties of base fluid and nanoparticles.

\begin{tabular}{ccc}
\hline $\begin{array}{c}\text { Physical } \\
\text { properties }\end{array}$ & Base fluid (CMC) & Nanoparticle $(\mathrm{Cu})$ \\
\hline$C_{p}\left(\mathrm{~J} \mathrm{~kg}^{-1} \mathrm{~K}^{-1}\right)$ & 4179 & 385 \\
$\rho\left(\mathrm{kg} \mathrm{m} m^{-3}\right)$ & 997.1 & 8933 \\
$k\left(\mathrm{Wm}^{-1} \mathrm{~K}^{-1}\right)$ & 0.613 & 401 \\
$\beta \times 10^{5}\left(\mathrm{~K}^{-1}\right)$ & 21 & 1.67 \\
\hline
\end{tabular}

Comparison of results on the heat transfer rate with the various values of Prandtl number obtained in this study, with those of Sharidan et al. (2006) and Freidoonimehr et al. (2015) are presented in Table 4. These results reveals a good agreement, which validates the use of present scheme. In order to investigate the effect of different shapes on solid nanoparticles on the fluid flow and heat transfer characteristics of the present problem, the distribution of velocity and temperature as well as the variations of skin friction and heat transfer coefficients are depicted in Fig. $2-7$ and Table 5-6, respectively.

Table 4 Comparison results of the heat transfer rate, $\theta^{\prime}(0)$ for $\varepsilon=\Omega=\phi=\lambda=\alpha=K=0$ and various values of $\operatorname{Pr}$.

\begin{tabular}{cccc}
\hline $\operatorname{Pr}$ & $\begin{array}{c}\text { Sharidan et al. } \\
\mathbf{( 2 0 0 6 )}\end{array}$ & $\begin{array}{c}\text { Freidoonimehr } \\
\text { et al. (2015) }\end{array}$ & Present \\
\hline 0.72 & 0.8086 & 0.8086 & 0.8086 \\
1.0 & 1.0000 & 1.0000 & 1.0000 \\
3.0 & 1.9238 & 1.9237 & 1.9239 \\
10.0 & 3.7225 & 3.7207 & 3.7236 \\
\hline
\end{tabular}

Fig. 2 and 3 exhibit the influence of the material parameter, $K$ on the distribution of velocity and temperature for different shapes of nanoparticles, sphere, needle and disk-shaped. Fig. 2 reveals that, velocity profile, $f^{\prime}(\eta)$ increase for the increasing values of $K$ for different shapes of $\mathrm{Cu}$-nanoparticles at specific value of solid nanoparticles volume fraction, $\phi=0.02$. However, it also observed that influence of $K$ is more significant on the velocity profile compared to temperature. It is also noticed that, the temperature profile, $\theta(\eta)$ is reduced when the values of $K$ is enlarged as depicted in Fig. 3. On the other hand, from all these figure, it can be concluded that, the maximum velocity is achieved fo the needle-shaped nanoparticles followed by disk and sphere-shaped nanoparticles at any values of $K$. It is also 
noticed that, the disk-shaped nanoparticles have the maximum temperature followed by the needle and sphere-shaped nanoparticles.

Further, Fig. 4 to 7 are plotted to analyze the effect of $\phi$ in different shapes of nanoparticles with and without the present of material parameter, $K$. Both figures shows that, the velocity profiles increases with the increasing of solid nanoparticles volume fraction for both needle and disk-shaped nanoparticles while the reverse behaviour is observed for the sphere-shaped nanoparticles for both cases, $K \approx 0$ (Newtonian fluid) and $K=1$ (second grade fluid). According to the physical expectation, the addition of the solid nanoparticles makes the fluid more viscous and thus, slows down the fluid flow as showed for the behaviour of sphere-shaped nanoparticles on the velocity profile. However the contradict behaviour is observed for needle and diskshaped nanoparticles. The contradict behaviour is observed for both cases, with the presence or absence of material parameter.

Furthermore, it is found in Fig. 6 and 7 that, the temperature profiles, $\theta(\eta)$ increase with the increase in solid nanoparticles volume fraction, $\phi$ for sphere, disk and cylinder-shaped nanoparticles. Physically, if the volume fraction increases, the thermal conductivity also increases which leads to the increasing of thermal boundary layer thickness. These physical behaviour agree very well with the previous studies reported by Timofeeva et al. (2009), Aaiza et al. (2015) and Ellahi et al. (2016). It is examined in Fig. 7 that, the influence of solid nanoparticles volume fraction on the temperature distribution are seen to be more substantial with the presence of material parameter. Based on Fig. $4-7$, it can be concluded that, the needle-shaped nanoparticles give the maximum velocity, while the maximum temperature is achieved for disk-shaped nanoparticles for both cases, $K \approx 0$ (Newtonian fluid) and $K=1$ (second grade fluid).

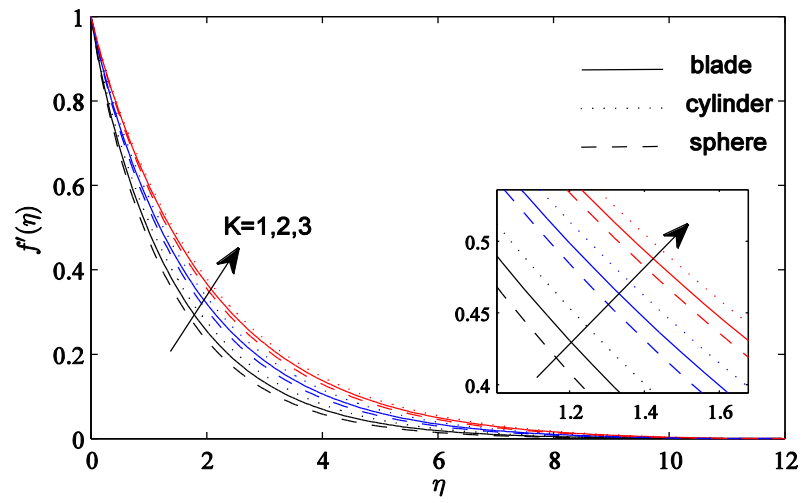

Fig. 2 Velocity profile on the various values of $K$ for sphere-shaped, needle-shaped (cylinder) and disk-shaped (blade) nanoparticles at $\phi=0.02$.

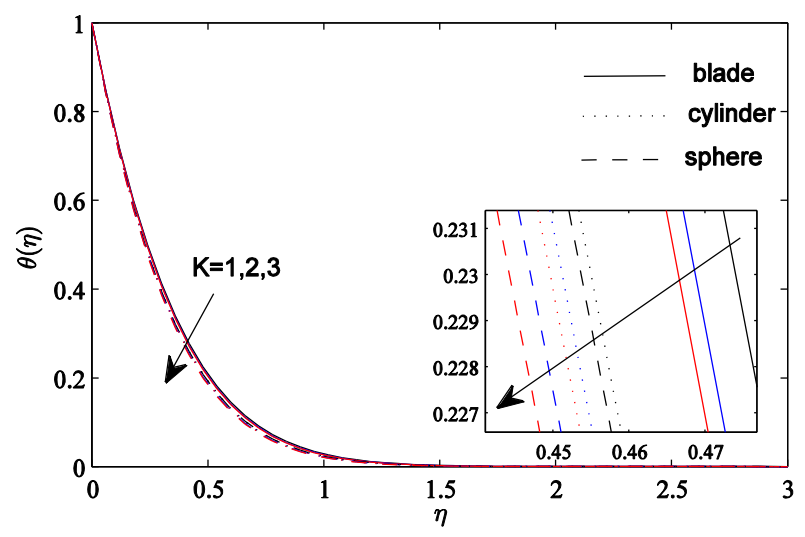

Fig. 3 Temperature profile on the various values of $\mathrm{K}$ for needle-shaped (cylinder) and disk-shaped (blade) nanoparticles at $\phi=0.02$.

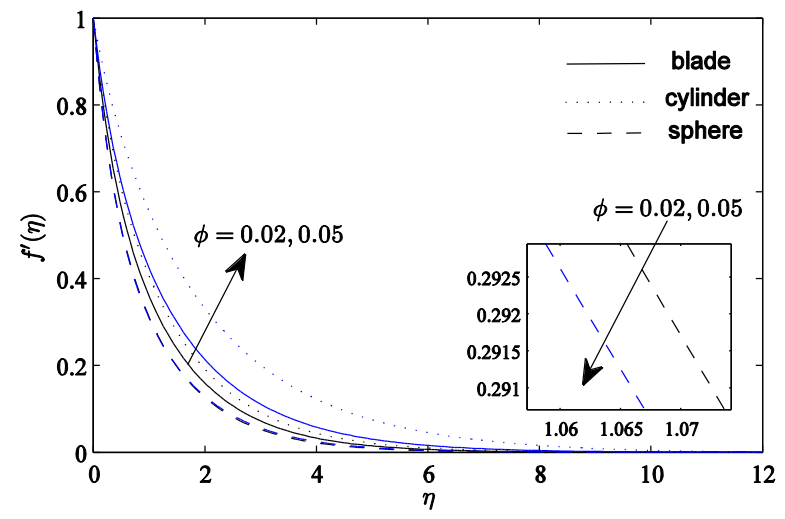

Fig. 4 Velocity profile on the various values of $\phi$ for sphere-shaped, needle-shaped (cylinder) and disk-shaped (blade) nanoparticles at $K=0$.

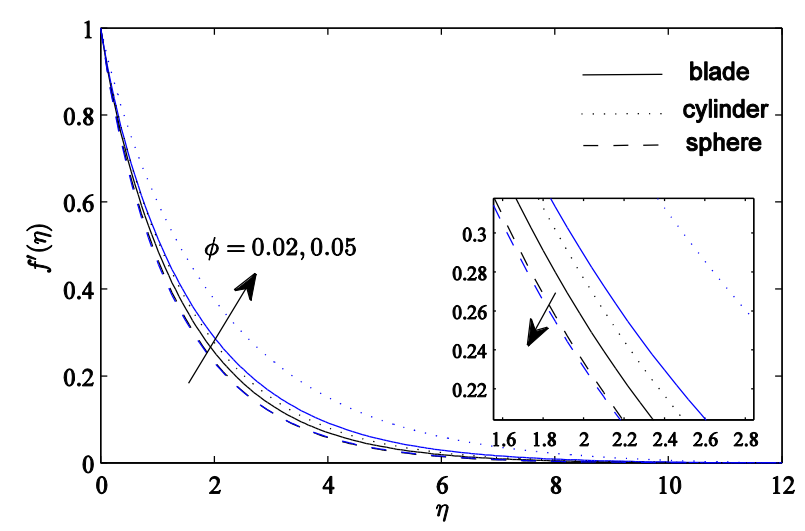

Fig. 5 Velocity profile on the various values of $\phi$ for sphere-shaped, needle-shaped (cylinder) and disk-shaped (blade) nanoparticles at $K=1$.

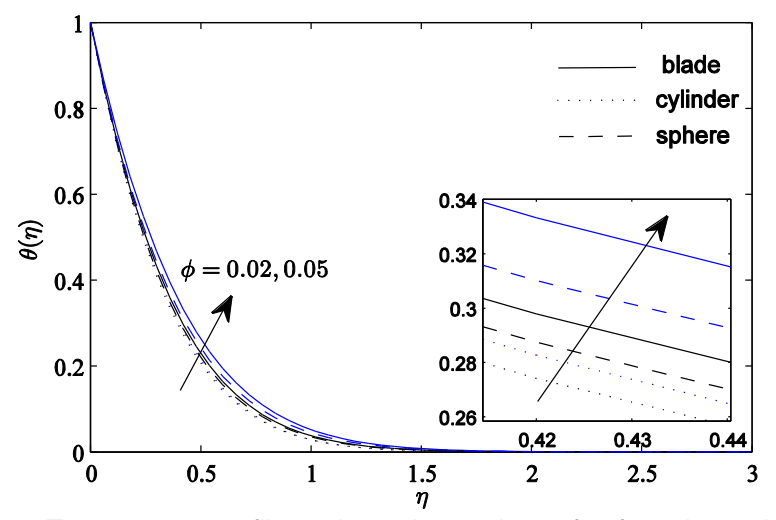

Fig. 6 Temperature profile on the various values of $\phi$ for sphere-shaped, needle-shaped (cylinder) and disk-shaped (blade) nanoparticles at $K=0$.

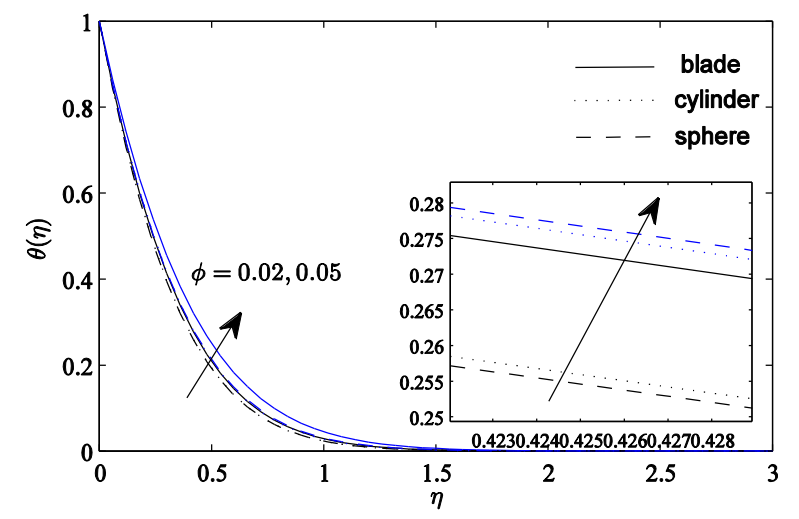

Fig. 7 Temperature profile on the various values of $\phi$ for sphere-shaped, needle-shaped (cylinder) and disk-shaped (blade) nanoparticles at $K=1$. 
The numerical results in Tables 5 and 6 illustrate the effects of amplitude of modulation, $\varepsilon$, frequency of oscillation, $\Omega$ on the variations of skin friction, $-f^{\prime \prime}(\tau, 0)$ and heat transfer coefficients, $-\theta^{\prime}(\tau, 0)$ of sphere, needle and disk-shaped nanoparticles for different values of solid nanoparticles volume fraction, $\phi$. It can be seen that, with the increase of amplitude of modulation and frequency of oscillation, the skin friction and heat transfer coefficients decreases and increases, respectively. Furthermore, the increasing values of $\phi$ leads to increase the values of skin friction and heat transfer coefficients as shown in the comparison results between Table 5 and 6. Meanwhile, the highest enhancement of heat transfer coefficient due to the influence of solid nanoparticles can be seen on the needle-shaped nanoparticles compared to others shape. Needle and disk-shaped nanoparticles give the highest values of skin friction and heat transfer coefficients due to the influence of solid nanoparticles volume fraction as shown in both tables. Additionally, the influence of solid nanoparticles volume obviously gives the maximum enhancement on the skin friction coefficients for the needle-shaped nanoparticles.

Table 5 Variation of skin friction and heat transfer cofficients with different values of $\varepsilon$ and $\Omega$ for needle (cylinder), sphere, and diskshaped (blade) nanoparticles at $\phi=0.02$.

\begin{tabular}{ccccc}
\hline Shapes & $\Omega$ & $\varepsilon$ & $f^{\prime \prime}(\tau, 0)$ & $\theta^{\prime}(\tau, 0)$ \\
\hline \multirow{3}{*}{ Blade } & 0.1 & 0.3 & -0.784641 & -2.708683 \\
& & 0.6 & -0.784976 & -2.708602 \\
& 0.2 & 0.3 & -0.784618 & -2.708690 \\
& & 0.6 & -0.784915 & -2.708620 \\
\hline \multirow{3}{*}{ cylinder } & \multirow{2}{*}{0.1} & 0.3 & -0.734867 & -2.807820 \\
& & 0.6 & -0.735113 & -2.807761 \\
& 0.2 & 0.3 & -0.734850 & -2.807826 \\
& & 0.6 & -0.735069 & -2.807775 \\
\hline \multirow{2}{*}{ sphere } & 0.1 & 0.3 & -0.834708 & -2.834434 \\
& & 0.6 & -0.835071 & -2.834347 \\
& 0.2 & 0.3 & -0.834683 & -2.834442 \\
& & 0.6 & -0.835003 & -2.834368 \\
\hline
\end{tabular}

Table 6 Variation of skin friction and heat transfer cofficients with different values of $\varepsilon$ and $\Omega$ for needle (cylinder), sphere, and diskshaped (blade) nanoparticles at $\phi=0.05$.

\begin{tabular}{ccccc}
\hline Shapes & $\Omega$ & $\varepsilon$ & $f^{\prime \prime}(\tau, 0)$ & $\theta^{\prime}(\tau, 0)$ \\
\hline \multirow{3}{*}{ Blade } & 0.1 & 0.3 & -0.728956 & -2.438922 \\
& & 0.6 & -0.729247 & -2.438848 \\
& 0.2 & 0.3 & -0.728937 & -2.438928 \\
& & 0.6 & -0.729194 & -2.438860 \\
\hline \multirow{3}{*}{ cylinder } & \multirow{2}{*}{0.1} & 0.3 & -0.561021 & -2.652622 \\
& & 0.6 & -0.561121 & -2.652599 \\
& 0.2 & 0.3 & -0.561014 & -2.652625 \\
& & 0.6 & -0.561104 & -2.652605 \\
\hline \multirow{3}{*}{ sphere } & 0.1 & 0.3 & -0.861796 & -2.692275 \\
& & 0.6 & -0.862190 & -2.692178 \\
& 0.2 & 0.3 & -0.861767 & -2.692283 \\
& & 0.6 & -0.862112 & -2.692201 \\
\hline
\end{tabular}

\section{CONCLUSION}

The influence of the shapes of nanoparticles on the mixed convection flow of second grade nanofluid past an inclined stretching sheet together with the g-jitter effect is studied in this paper. Three different shapes of copper nanoparticles is considered, sphere, needle and disk-shaped nanoparticles. The effects of the amplitude of modulation, frequency of oscillation, solid nanoparticles volume fraction and material parameter on the fluid flow are discussed in detail. It is found that, the highest velocity and temperature as well as the skin friction and heat transfer coefficients of second grade nanofluid is achieved for the needle and disk-shaped nanoparticles.

\section{ACKNOWLEDGEMENT}

The authors would like to acknowledge Ministry of Higher Education (MOHE) and Research Management Centre-UTM for the financial support through vote numbers 4F713, 15H80 and 13H74.

\section{REFERENCES}

Aaiza, G., Khan, I., Shafie, S. 2015. Energy transfer in mixed convection MHD flow of nanofluid containing different shapes of nanoparticles in a channel filled with saturated porous medium. Nanoscale Res. Lett. 10, 1-14.

Benchabane, A., Bekkour, K. 2008. Rheological properties of carboxymethyl cellulose (CMC) solutions. Colloid Polym. Sci. 286, 1173-1180.

Buongiorno, J. 2006. Convective transport in nanofluids. J. Heat Transfer. 128, 240-250.

Ellahi, R., Hassan, M., Zeeshan, A. 2016. Shape effects of spherical and nonspherical nanoparticles in mixed convection flow over a vertical stretching permeable sheet. Mech. Adv. Mater. Struct. 1-8.

Freidoonimehr, N., Rashidi, M.M., Mahmud, S. 2015. Unsteady MHD free convective flow past a permeable stretching vertical surface in a nano-fluid. Int. J. Therm. Sci. 87, 136-145.

Hamilton, R.L., Crosser, O.K. 1962. Thermal conductivity of heterogeneous two-component systems. Ind. Eng. Chem. Fundam. 1, 187-191.

Hayat, T., Ashraf, M. B., Alsulami, H. H., Alhuthali, M. S. 2014. Three dimensional mixed convection flow of viscoelastic fluid with thermal radiation and convective conditions. PloS One. 9, 1-11.

Hayat, T., Qasim, M. 2011. Radiation and magnetic field effects on the unsteady mixed convection flow of a second grade fluid over a vertical stretching sheet. Int. J. Numer. Methods Fluids. 66, 820-832.

Hsu, C.H., Chang, Y.P., Chen, B.C. 1999. Transient mixed convection of a second-grade fluid past a backward-facing step. Int. J. Non Linear Mech. 34, 881-893.

Karagoz, B., Esser, L., Duong, H.T., Basuki, J.S., Boyer, C., Davis, T.P. 2014 Polymerization-Induced Self-Assembly (PISA)-control over the morphology of nanoparticles for drug delivery applications. Polym. Chem. 5, 350-355.

Lin, Y., Zheng, L., Zhang, X. 2014. Radiation effects on Marangoni convection flow and heat transfer in pseudo-plastic non-Newtonian nanofluids with variable thermal conductivity. Int. J. Heat Mass Transfer. 77, 708-716.

Mushtaq, M., Asghar, S., Hossain, M.A. 2007. Mixed convection flow of second grade fluid along a vertical stretching flat surface with variable surface temperature. Heat Mass Transfer. 43, 1049-1061.

Qasim, M., Hayat, T., Obaidat, S. 2012. Radiation effect on the mixed convection flow of a viscoelastic fluid along an inclined stretching sheet. $Z$. Naturforsch. A: Phys. Sci. 67, 195-202.

Ramzan, M., Bilal, M. 2015. Time dependent MHD nano-second grade fluid flow induced by permeable vertical sheet with mixed convection and thermal radiation. PloS One. 10, 1-25.

Sharidan, S., Amin, N., Pop, I. 2006. g-Jitter mixed convection adjacent to a vertical stretching sheet. Microgravity Sci. Technol. 18, 5-14.

Timofeeva, E.V., Routbort, J.L., Singh, D. 2009. Particle shape effects on thermophysical properties of alumina nanofluids. J. Appl. Phys. 106, 1-10.

Tiwari, R. K., Das, M. K. 2007. Heat transfer augmentation in a two-sided liddriven differentially heated square cavity utilizing nanofluids. Int. J. Heat Mass Transfer. 50, 2002-2018.

Turkyilmazoglu, M. 2013. The analytical solution of mixed convection heat transfer and fluid flow of a MHD viscoelastic fluid over a permeable stretching surface. Int. J. Mech. Sci. 77, 263-268.

Wong, K. V., De Leon, O. 2010. Applications of nanofluids: current and future. Adv. Mech. Eng. 2, 1-11. 